\title{
CATALANO, THERESA, TALKING ABOUT GLOBAL MIGRATION. IMPLICATIONS FOR LANGUAGES TEACHING. BRISTOL: MULTILINGUAL MATTERS, 2016, 220 PÁGS. ISBN: 978178309554
}

\author{
DOINA REPEDE \\ Universidad de Sevilla \\ doinarepede@gmail.com
}

The main purpose of this book is to describe a complex and insufficiently understood phenomenon in education and society in general: the lives of migrants crossing borders, and, specially, their struggle to run away from poverty or conflict to pursue a better quality of life, education or security.

The book masterfully explores the stories of 77 migrants from 41 countries around the world and analyses the language they use when relating their move to a different country and their lived experiences there. In other words, it is about a personal journey that captivates readers with individualized stories, so it is impossible for them not to be touched by the travellers' voice. Their accounts reflect the diversified nature of migrant journey.

The volume is organized into four parts: Beginnings, The stories, The Metaphors and Metonymies and Conclusion and Future Directions. The first section begins with the chapter called "Introduction", where the goals of the book and the methodology are presented.

Chapter 2 in this part, "Terminology and Types of Migrants", defines and clarifies some of the terminology and research related to immigration and migrants. It also provides a list of the participants and the category in which their story appears (i.e. why they migrated).

In Chapter 3 "What are Metaphor and Metonymy?", the author explains what the analysis of these mechanisms entails, and why it is helpful for understanding how human migration is perceived by the migrants in this book.

Chapter 4 "Media Discourse and Migrants" is a brief review of metaphor research about immigration discourse and major findings in the area. Here, Theresa Catalano offers examples of how migrants are represented on media discourse: metaphors such as IMMIGRANTS ARE CRIMINALS, PARASITS or ANIMALS are often used to describe them. Thus, the author underlines that "this does not presents migrants in a good light, and many of the migrants who participated in this book had experiences that they have resulted from people's stereotypes or perceptions due the entrenchment of these metaphors" (p. 27).

Para citar esta reseña / To cite this book review: Repede, Doina (2017). Reseña de Theresa Catalano (2016): Talking about Global Migration. Implications for Languages Teaching. Bristol: Multilingual Matters (220 páginas). ELUA, 31: 383-385. doi:10.14198/ELUA2017.31.22

Enlace / Link: http://dx.doi.org/10.14198/ELUA2017.31.22 
Part 2 "The stories" describes the different types of migrants found in this study: adventure migrants, refugee/asylum seekers, family-reunion/child migrants, economic migrants, third culture kids and love and/or marriage migrants. In each one of these categories, several example stories are told in full, followed by a discussion of themes and/or metaphor found and their connections to educational and language issues. Accounts selected to be re-told in the book were chosen based on different criteria: variety of gender, diversion of origin and destination countries, assortment of story types, and identification of issues related to the book's focus.

Therefore, readers have the possibility to discover interesting themes from each of these accounts. They can learn from Michi that education isn 't just about a career and that non-traditional learning opportunities allow people to explore the world and know it subtly and deeply. Sachim, in search of a better quality of life, prefers happiness to opulence. For Lihua, it is more about seeking acceptance. Imran shows the relevance of understanding the humour of the receiving country. Bertha underscores the importance of newcomers knowing their rights in the new country and gaining access to help such as how to find safe housing or how to find out what services they are eligible for.

In his story, Badr emphasises the necessity of co-existence, good attitude and living nobly. The narrative of Arman and Carmelle underlines the issue of silence: Arman isn't able to relate his story because he doesn't want to re-live the experience, and Carmelle considers that migrants should accept their situation and remain silent. Contrarily, Emma highlights the need of having an open mind and realizing that different does not mean bad. Thinh's story reveals the feeling of foreignness in school and "the social and academic isolation that can occur from being singled out as different" (p. 91).

The third section presents two parts. It begins with the Chapter 11 "Summary of Dominant Metaphors/Metonymies in the Stories", where the findings from the metaphor analysis of the stories (including stories not told in this book, but that were part of the study) are discussed and dominant metaphors/metonymies are broken down in order teachers understand their implication.

Two types of metaphors are prevailing in this book: IMMIGRATION AS A JOURNEY and IMMIGRATION AS CULTIVATION. The first one dominates in migrants' discourse. Immigration is presented as a significant part of the metaphor of 'Life is a journey' which implies a beginning, middle and end. It also means "a path to take, various choices to make along the road, twists and turns and setbacks to overcome, a guide to help on the journey, and eventually arriving at the destination" (p. 154). The whole process can be a successful integration into the host culture or not.

In this book, the author reflects that just any physical journey, these travellers had to face different, and individualized, barriers that impeded their path. For Yan and Hui it was language. In case of Placida, it was about understanding the culture. Kofi had to overcome the racial division he found in the receiving country.

The second metaphor indicates the transformative power of migration as a personal accomplishment. In the case of Sachin, migration experience made him wiser. For Carmelle, this process meant a lot of responsibility. Xui had to adapt to a new environment and this experience brought colour to her life. Julieta revealed personal growth and attainment. Cristina highlighted the importance of being able to express oneself in a language.

In Chapter 12 "Media Discourse vs. Migrant Discourse", the metaphor analysis findings are compared to metaphors found in media discourse about migrants. The main goal of this 
chapter is consciousness-raising: by showing how the migrants describe themselves and their experiences and how the media discourse represents them, readers can think more about the way in which they talk about this complex subject and how it forms their thinking patterns.

Part 4 includes the last chapter of this book "Conclusions and Future Directions". Here, the author sums up the most important findings of this study and discusses future direction for the project.

Finally, in order to help teachers of undocumented adolescents or adult undocumented students, the book includes an appendix with resources for migrants lacking documents for legal residence in different countries (US, EU, UK and South Africa).

In this volume, Theresa Catalano attempts to explain and improve our understanding of migration by paying close attention to the migrants' discourse. Thus, teachers, and readers in general, can learn in terms of stories themselves and in terms of metaphor analysis. The author also offers them various advices and suggestions on immigration questions.

This exceptional book based on the theme of migrant experiences and his insights into global migration is a valuable contribution to the field. 